\title{
Let's talk about sex: How people with intellectual disability in Australia engage with online social media and intimate relationships
}

\author{
Judith Darragh, Louise Reynolds, Caroline Ellison, \& Michelle Bellon \\ Faculty of Medicine, Nursing and Health Sciences, Flinders University, Bedford Park, Australia
}

\begin{abstract}
People with intellectual disability often experience repression and control of their sexuality as they have historically been perceived as being childlike and asexual by members of society. Such acts can be seen to contravene their Human Rights under The Convention on the Rights of Person with Disabilities (CRPD), which endorses the rights of people with intellectual disability to fully express their sexuality.

The purpose of this study was to explore if people with intellectual disability access internet based social media, and if so, if they use it to form relationships that express their sexuality.

Using an interpretative phenomenological approach, semi-structured interviews were conducted with 30 adults with an intellectual disability (22 males, 8 females), aged between 20 to 66 years. Participants were purposely sampled though disability organisations.

Three themes emerged from the data: creating new friendships, maintaining existing friendships, exploring and expressing sexuality. People with intellectual disability used a variety of personal electronic devices to access internet based social media to be socially and sexually active. Facebook was accessed to make contact with existing platonic friends, peers and interest groups to meet socially. Sexually explicit material was viewed using the internet, either as an individual activity or by couples in monogamous relationships.

This study adds to the paucity of research examining the use of internet based social media by people with intellectual disability for sexual expression. This research revealed the people with intellectual disability exercised cyber safe practices without any explicit formal education and conducted themselves in a respectful manner. Few participants acted in a manner that appeared to put them at risk of exploitation.
\end{abstract}

Keywords: intellectual disability; internet based social media; relationships; sexuality; Gatekeeper

\section{Introduction}

Given that 'communication is the keystone of social life' (Seymour \& Lupton, 2004, p. 291), the internet and tools such as internet based social media which can be accessed through personal electronic devices have changed the way humans communicate, interact, instigate, grow, maintain and develop relationships (Correa, Hinsley, \& de Zúñiga, 2010; Gutiérrez \& Martorell, 2011; Raacke \& Bonds-Raacke, 2008; Reid \& Boyer, 2013). However, for some of society's most marginalised people, internet based social media remains inaccessible due to the design and functionality of various applications, lack of computer or device access, as well as poor or limited literacy skills which were not acquired or developed during formative years of education (Chadwick, Wesson, \& Fullwood, 2013). 
Despite the rapid evolution of technology, limited access to internet based social media by people with intellectual disability reflects their experience of social exclusion and being devalued (Batey \& Waine, 2015; Shakespeare, 2008). Discourse around the notion of the existence of a 'digital divide', Chadwick et al (2013) point out that it is not known how many people with intellectual disability access internet based social media. It is anticipated that the benefits for people with intellectual disability (as with all users) of connecting with others include reduced isolation and stigma, and development of social relationships that underpin and facilitate an understanding of their sexuality (Batey \& Waine, 2015; D'Aubin, 2007; Dobransky \& Hargittai, 2006; Jaeger, 2012).

Seminal texts describe the factors which may hinder people with intellectual disability from developing their sexuality (Hollomotz 2011; Kulick \& Rydstrom, 2015; McRuer \& Mallow, 2012; Shakespeare, Gillespie-Sells \& Davies, 1996). Major influences affecting the sexual development of people with intellectual disability stem from societal beliefs and myths that have resulted in stereotypical portrayals in media which have, in turn, influenced restrictions and control placed on their sexual development (Goggin, 2009). Common stereotypes of people with intellectual disability as asexual, eternally childlike, naïve or potentially sexually deviant and unable to control sexual urges (Brown, 1994; Di Giulio, 2003; Franco, Cardoso, \& Neto, 2012; McDonagh, 2007; Murphy, 2003; Sweeney, 2007) are based on fears and myths which can be a barrier when engaging with other members of society (Swango-Wilson, 2010). In addition, various social control methods have historically been employed, ensuring people with intellectual disability were fearful of engaging in intimacy, which was often reinforced with punishment (Löfgren-Mårtenson, 2008).

In addition, barriers to accessing the internet and internet based social media have further hindered the exploration and expression of sexuality by people with intellectual disability. This results in fewer opportunities for: further education; information; engagement in pleasurable sexual experiences; developing and maintaining intimate and sexual relationships; marriage; and children (Lazar \& Jaeger, 2011; Swango-Wilson, 2010). Those preventing access have been identified and named as 'gatekeepers', often parents and carers of people with intellectual disability who may control access to internet based social media and personal electronic devices. While well-intentioned, gatekeepers may view people with intellectual disability as gullible or vulnerable to exploitation (Parley, 2010) and require control and protection over internet based content, banning pornography or viewing violent sites (Löfgren-Mårtenson, 2008). However, the contrary remains true with restrictions to appropriate social and sexual interactions leaving people with intellectual disability more vulnerable to exploitation and inappropriate sexual relationships (Bruder \& Kroese, 2005; Sweeney, 2007).

Sexuality is an important characteristic of being human (Craft, 1987; Parchomiuk, 2012). In principle, this is a rarely contested view for those living without a disability, who may live with the opportunity to freely express and engage in sexual activities. Yet, in reality, sexuality remains problematic for some people with intellectual disability (McCarthy, 2014). The tension remains, therefore, for many groups in society, including those with an intellectual disability, that for various reasons such as ethnicity, religion or other cultural practices, this freedom is not encouraged nor supported.

The repression and control of people with intellectual disability from expressing their sexuality can be viewed as a denial of their human rights. Societal attitudes towards the sexuality of people with intellectual disability need to be challenged in order to fulfil the human rights commitment and obligation as outlined in the CRPD (United Nations, 2006). This requires positive acceptance and acknowledgement of their entitlement to the same opportunities as all in society (Löfgren-Mårtenson, 2004). One such opportunity is access to internet based social media.

Although the internet is now firmly entrenched in mainstream society, access to the internet has highlighted the inequalities which exist for some groups, and people with intellectual disability in particular (Chadwick et al, 2013; Stendal, 2012). Not only does the internet enable people with intellectual disability to express their sexuality to engage in meaningful relationships, but all types of associations, as not all contact need necessarily be sexually based. It is understood that people with intellectual disability desire to make friends and have meaningful relationships with them. However, in reality they have fewer friends and the ones that they do talk about are mostly paid carers, family and/or other people with intellectual disability (Amado, Stancliffe, McCarron \& McCallion, 2013). Given that intimacy and relationships are complicated enough for those who live without an intellectual disability (Bazzo, Nota, Soresi \& Minnes, 2007), it is even more so for those people with intellectual 
disability whose experience of relationships, sex, love and intimacy is not always a private affair due to the lack of privacy, especially when living in shared accommodation (Rogers, 2009).

The aim of this study is to explore if people with intellectual disability access internet based social media, and if so, do they use it to form relationships that express their sexuality.

\section{Method}

A qualitative research design was adopted, namely Interpretative Phenomenological Approach (IPA) (Pietkiewicz \& Smith, 2014; Smith, 1996; Smith, Flowers, \& Larkin, 2009; Smith \& Osborne, 2003). Based on this approach a rich description of the lived experience of people with intellectual disability explored whether (or not) and how they have formed intimate relationships through internet based social media (Van der Zalm \& Bergum, 2000). Taking an IPA allowed the researcher flexibility in exploring the phenomena studied (Lincoln \& Guba, 1985), namely the lived experience of people with intellectual disability and how they make meaning of accessing internet based social media and their intimate relationships with others, rather than explaining or generating a theory (Mackey, 2005; Van der Zalm \& Bergum, 2000). The researcher gains an understanding of this phenomena from the participant's perspective (Collingridge \& Gantt, 2008; Delaney, 2003), hence they are only interested in the experience and meaning held by the participants and how these meanings vary in order to challenge existing structural or normative assumptions (Lester, 1999).

There are a number of schools of phenomenology (Dowling \& Cooney, 2012); while some share commonalities they also have distinct characteristics. The philosophies of Edmund Husserl (1859-1938), acknowledged as the 'founding father' of the phenomenological movement, are quite distinct from that of his pupil Martin Heidegger (1889-1976) related to the way in which they influence the interview process, the generation of data and the role of the researcher (Lowes \& Prowse, 2001). What emerged were two main phenomenological approaches: descriptive (eidetic) and interpretative (hermeneutic) (Cohen \& Omery, 1994). The descriptive approach to phenomenological enquiry came from Husserl's philosophical ideas (Flood, 2010) and is the study of 'things as they appear' in order to arrive at an unbiased and rigorous understanding of the human thought and experience (Liamputtong, 2009). Husserl's fundamental concern was an epistemological one. To provide a foundation for knowledge (Todres \& Wheeler, 2001), he believed that contact to the material world was through consciousness and that all knowledge was gained from experience (Priest, 2002). In contrast, a Heideggerian phenomenology approach focuses on the person and the context of their existence (Mackey, 2005).

Drawing on and being sympathetic to phenomenology, IPA extends this perspective by being dynamic in using double interpretation process by describing and interpreting the experience (Pietkiewicz \& Smith, 2014). This allows the researcher to collect the views of participants and describe the commonalities of their experience of a phenomenon from the participants' detailed statements and experiences (Creswell, Hanson, Clark, \& Morales, 2007; Smith, 1996). This approach is congruent with the aim of this study as it seeks to give people with intellectual disability a 'voice' to express the experiences of using internet based social media in their everyday life when engaging in relationships, thereby giving the researcher an understanding of their perspective to accurately interpret and report their personal thoughts and experiences (Lowes \& Prowse, 2001).

\section{Sampling Strategy and Participant Recruitment}

In order to gain access to people with intellectual disability, the researcher contacted disability service organisations known to her as recommended by colleagues and peers. This was done with institutional (Flinders University) review board approval through Social and Behavioural Research Ethics Committee, so that the researcher could approach disability organisations to explain the aims of the study to obtain their support and access to participants. As part of the conditions of the institutional (Flinders University) review board approval, the researcher was required to approach a representative of the employment organisation to distribute information and consent brochures that gave comprehensive details about the study. In this phase the initial approach was adopted as a method of building good relationships with key contacts as they were viewed as stakeholders in this process to gain access to participants who were deemed a vulnerable group (MacDougall \& Fudge, 2001). Tailor-made information sheets were produced which were written in a reading level appropriate using specific language about the research project with the view that it would help establish these relationships. 
This involved connecting with organisations by email, telephone and/or in person to explain the study purpose, research processes and the role of the researcher to stakeholder organisations.

The participants with intellectual disability were chosen by organisational representatives which, as part of the Institutional (Flinders University) review board ethics approval process, meant there was no direct contact or coercion for participation in the research project. They were: aged over 18 years of age; eligible to receive the disability support pension and/or had been assessed as having an intellectual disability and/or were eligible to receive services from government and non-government agencies; interested and willing to be involved in the study; able to understand questions and provide answers either verbally or using an augmented communication system; and geographically available to the researcher (see Table 1). Participants selected by the disability organisation representative fulfilled each of the above criteria.

Table 1. Participant's Profile.

\begin{tabular}{|c|c|c|c|c|c|}
\hline & $\begin{array}{l}\text { Age } \\
\text { range }\end{array}$ & Employment & Social media & $\begin{array}{l}\text { Personal } \\
\text { electronic } \\
\text { devices }\end{array}$ & \\
\hline \multirow[t]{5}{*}{$\begin{array}{l}\text { Males } \\
N=22\end{array}$} & $20-30$ & $\begin{array}{l}\text { Volunteering roles, } \\
\text { part time and full } \\
\text { time and retired }\end{array}$ & $\begin{array}{l}\text { No access or cannot } \\
\text { access internet } \\
\text { Can access and uses } \\
\text { internet and social } \\
\text { media sites such as } \\
\text { Facebook and Twitter }\end{array}$ & $\begin{array}{l}\text { Mobile phone, } \\
\text { tablet, laptop and } \\
\text { desk top } \\
\text { computers }\end{array}$ & $\begin{array}{l}\text { Jonnie, John, Elvis, } \\
\text { Jacob, Andy, Justin, } \\
\text { Angelo, Brendan, } \\
\text { Chris, Paul, Liam, } \\
\text { Leigh }\end{array}$ \\
\hline & $30-40$ & & & & $\begin{array}{l}\text { James, Cam, Hallsy, } \\
\text { lan, Martin }\end{array}$ \\
\hline & $40-50$ & & & & $\begin{array}{l}\text { Garry, Daniel, } \\
\text { Greenie }\end{array}$ \\
\hline & $50-60$ & & & & Robert \\
\hline & 66 & & & & Clem \\
\hline $\begin{array}{l}\text { Females } \\
N=8\end{array}$ & $26-30$ & $\begin{array}{l}\text { Part time, fulltime } \\
\text { and retired }\end{array}$ & $\begin{array}{l}\text { No access (not allowed), } \\
\text { would like access - or } \\
\text { has access to Facebook, } \\
\text { Myspace, Instagram }\end{array}$ & $\begin{array}{l}\text { Mobile phone, } \\
\text { laptop and tablet }\end{array}$ & Ellie, Stella \\
\hline & $30-40$ & & & & Katie, Paris, \\
\hline & $40-50$ & & & & Rachael, \\
\hline & $50-60$ & & & & Christie, Helen \\
\hline & $60+$ & & & & Josie \\
\hline
\end{tabular}

\section{Data Collection}

Semi-structured in-depth interviews with the 30 participants allowed the researcher to delve deeply into their social and personal experiences of internet based social media and relationships (DiCicco-Bloom \& Crabtree, 2006). Interviews were audio recorded with permission of participants, lasted from 30 to 60 minutes and were conducted either at the participant's home or place of employment.

The format of the interviews contained unstructured and generally open-ended questions, few in number, intended to extract participant's own views and experiences. Participants were allowed and encouraged to freely provide their views and experiences of using internet based social media and their relationships to the researcher (Creswell, 2014).

Despite the questions being ethically approved by the institutional (Flinders University) review board and developed in consultation with a professional practitioner working for many years in the disability and sexuality field, one disability organisation intermediary censored several questions citing them to be inappropriate to ask. They were deemed 'too personal' as they pertained to asking about participant's sexual feelings. The full 
interview guide is presented in Appendix, with questions appearing in 'bold' censored and deleted from the interviews with eleven participants from that site.

\section{Data Analysis}

Qualitative analysis is a methodical, continuous process of observing, recording, reviewing and interpreting data to explain the phenomenon being studied (Fossey, Harvey, McDermott, \& Davidson, 2002). Amalgamating the various identified themes allows meaningful relationships with the core elements of the person's experiences to be formed, which emerge as categories that require further analysis (Liamputtong, 2009). This allows for 'bottom up' approach for the emergent themes to then be interpreted, with both description and interpretation to be weaved concurrently which is consistent with IPA as a methodology (Smith et al, 2009).

Accordingly, the researcher recognised the iterative nature of the data analysis process and personally transcribed all recorded interviews $(n=30)$. After each interview, Microsoft Word was used to produce a transcript in which the preliminary data analysis was undertaken. A separate table was produced where those emerging ideas were examined, compared and contrasted with each other in order to identify any reoccurring themes. The different themes and meanings were sorted and organised to identify patterns and connections. The first readings of transcripts, combined with discussions and re-readings with research supervisors assisted with linking and strengthening of ideas, concepts, coding categories and emergent themes. Careful consideration of the data collected after each participant interview was further refined, with the identified themes and the establishment of new themes that required modification, highlighted the ongoing iterative feedback and feedforward data analysis process (Liamputtong, 2009).

\section{Results}

Almost half of participants $(n=13)$ described that they accessed internet based social media in order to create new friendships or maintain existing social friendships with peers. Five participants indicated they had viewed pornography to explore sexuality, one participant explored their sexuality by meeting new people (using on-line dating) and engaging in sexually intimate activities, and another engaged in an intimate activity using the camera function in internet based social media ('camming') for the explicit purpose of exploring sexual activities in real time with another person.

The following three themes were identified: (a) creating new friendships; (b) maintaining (existing) friendships; (c) exploring and expressing intimacy. Each theme is described below with direct quotes from participants. Pseudonyms have been used to protect confidentiality of participants.

\section{Creating New Friendships}

Using internet based social media, most participants expressed a desire to make new friends outside of existing peer groups, not known to them through their existing work or social groups. Some described feeling lonely and sought connection to expand their current friendship network. They were able to use their personal electronic devices and internet based social media to search for new friends. Helen (59 years old) stated: "[Facebook] really helped me; I get to meet a lot more people, a lot more friends... Before all this happened [Facebook] it was sort of really me and that was it, nothing else". Jonnie (20 years old) told how he arrived home one day: "there were 5 of them [friend] requests. I didn't even know them but I added them because I know it's the only way to make friends, you get to know them well enough".

Assessing, managing \& mitigating risks. Participants exercised considerable judgement in assessing, managing, and mitigating the risks associated with meeting for the first time those newly made online friends. Such judgements were informed, not by formal education, but rather their own intuition of what constituted personal cyber safe practices. They were able to clearly articulate what were the key risks associated with meeting someone that they did not know. Ellie (26 years old) said “Well you don't know the person you are meeting up with so something bad could happen like you could get raped or something like that. Umm yeah anything could happen if you meet someone that you don't know". 
Paris (31 years old) responded "If I want to meet someone I'll try and umm wait awhile to meet them because I would rather get to know them first before I meet them just in case they may be a paedophile or anything".

Leigh (28 years old) stated that:

"People can scam you on Facebook they can scam you. You can go and some people can dress up like a real girl or dress up or pretend to be someone else and then they can scam and show up as an old man and take advantage of you or something like that on Facebook. It can happen".

Participants were able to describe how they would manage those risks when meeting someone for the first time: Stella (26 years old) said: "I'd get someone to come with me. And I would take my phone as well. I take my phone everywhere so that I can contact the Police if something happened".

Angelo (29 years old) responded:

"I probably would meet in an open area so everybody, I wouldn't meet in like maybe a park, I wouldn't meet at a park or meet probably somewhere like a shopping centre or umm a pub or something like that, not in like a secluded place".

James (35 years old) wasn't quite sure but said "just meet in a public place somewhere, I don't know where not somewhere not dark". Christie (55 years old) said: "going to a crowded place, like a restaurant or a café, you know what I mean? If you want to have a coffee and catch up then a crowded place".

Finally, examples of mitigating risks were presented through descriptions of what they would do if they were feeling unsafe.

Brendan (24 years old) said:

"I tend not to be take weapons or anything with me because I'm not a violent type of person. Umm but I always keep my phone on me if I get into a bit of trouble...and if something doesn't quite work out I normally ring someone for help or if there is a local shop or something open l'll go and ask for some help".

Paris (31 years old) explained: "would most probably meet them in a public area where there are other people around me umm so then if anything does happen I can ask for help through people like that". Christie (55 years old) said: "I'd probably let one of my kids know so that if anything happens at least they know". While Ellie (26 years old) said she would "Make sure I carry my mobile on me because then I'll have someone to ring in case something does go bad".

These examples demonstrate participant's ability to assess, mitigate and manage risk associated with their personal cyber safety. What is evident is that people with intellectual disability can clearly identify a range of risks associated with their internet based social media and personal electronic device usage, assess and formulate strategies to mitigate them. This understanding was gathered, not from formal education, but from their own understanding and self-awareness of the environment.

Gatekeeping. While expressing their desire to meet new people, some participants were unable to gain access to both personal electronic devices and internet based social media by family members. For example, some participants expressed a desire to have access to a mobile phone and internet based social media, but were prevented by a family member who had cited concerns regarding personal safety issues. Rachael (43 years old) stated "my mum won't let me use um Facebook for safety reasons", however when further queried 'safety reasons' Rachael (43 years old) was not sure what they were. Katie (30 years old) also described her parent's rules, stating that their parent had directed her: "You can play games but that's all you can do on the Internet, nothing else".

Other participants who used personal electronic devices and internet based social media described surveillance behaviours by caregivers such as checking up on their online and social media activity. For example, Justin (22 years old) stated that his mother told him "you can't look at pornographic stuff". Justin (22 years old) told her "I 
don't do that stuff". Justin (22 years old) also reported that his mother checks his phone, looking for pornographic images, and told him "don't go onto any of the, those things [pornographic sites]".

Examples of gatekeeping included preventing people with intellectual disability access to personal electronic devices and internet based social media, family members warning participants not to look at certain things online and surveillance of activities. Those who are unable to access personal electronic devices and internet based social media risk being isolated and deprived of the potential to make new friends online.

\section{Maintaining (Existing) Friendships}

Participants reported that their primary use of internet based social media was to maintain existing friendships made while at school or their place of employment and to engage with hobby/interest groups. This was primarily through the use of Facebook on their personal electronic devices (mobile phone). Stella (26 years old) stated "I use my mobile because my mobile is linked to Facebook and the Internet".

Participants kept in touch with their friends by sending and receiving communications such as messages, emails or text short message service (SMS / text). The key internet based social media platform that was used to keep in contact with their friendship group was Facebook as it provided a message function they were able to use. Cam (36 years old) used the message function because he was: "mostly on social media because a telephone is a lot of money if you ring up all the time". The intention of the communication was to keep in contact as well as making arrangements to meet friends face to face for social outings.

People with intellectual disability in this study engaged in a range of social activities, for example: catching up, going out, meeting at the mall, going to the movies. Cam (36 years old) stated: "I just say...I do bowling every Wednesday and some of them just bowl umm bowl on a Wednesday or on a Thursday night so and I communicate with them". James (35 years old) reported having quite a few friends on Facebook who he makes plans to go out with for the day messaging "Can you meet at the train station?" They reply, "yeah, yeah" to which James messages back: "I'll meet you at the deli [delicatessen, milk bar or convenience store]". James explains that they all meet somewhere having made the arrangements on Facebook Messenger. Elvis (24 years old) stated that he arranges meetings via Facebook messenger: "I organise and say I'll meet you at Marion [large shopping mall] and this and that and I'll go meet them at Subway [sandwich bar]. Elvis (24 years old) also said that he sometimes "book[s] and meet[s] them down the bowling alley".

Social activities were mediated through participant's personal electronic device message function, whether on their mobile device (phone) or through the internet based social media message function. Participants were able to do so with their phone credit or internet data. Social activities were important as it meant that they were out in the community, using public transport to go to places such as the local mall or city centre. The purpose of the activity sometimes had a clear outcome (going to the movies) or purely social (hanging out / catching up).

When not communicating with their friends, they would be using the internet to search for old friends through internet based social media such as Facebook. Paris (31 years old) stated: "Umm I've used Facebook to find some of my old friends but only friends who I know".

Outside of work, other people with intellectual disability would engage in social activities associated with their interest or hobby. One participant, Garry (49 years old), used Facebook to post photographs to a photography group on Facebook. Garry stated "l enjoy it [Facebook]. I go on there to do my photography [hobby]. The people I do photography with say we are going out next weekend, and as a group we meet up. Yeah, makes [me] feel good". Elvis (24 years old) used Facebook to look at things that interested him: "looking from my phone, museum of cars, old cars".

Accessing personal electronic devices and internet based social media is an important method to maintaining existing friendships for people with intellectual disability. It facilitates their friendship by being able to send and receive communication, and arrange social activities. 


\section{Exploring and Expressing Intimacy}

Rather than using internet based social media, the internet was used by people with intellectual disability to explore and express their sexuality and intimacy. For both un-partnered individuals and those within consenting, monogamous relationships, the internet was used to access pornographic images or videos. When partnered, participants stated they viewed pornography only with permission of their partner, and discontinued when their partner expressed concern, dissent or disapproval.

For example, Andy (27 years old) looked at pornography with his girlfriend, and explained how: "you just go to a website...scroll down and click on it and then go on a video and you see it". When asked if he had looked for more pornography he said "nah stopped looking". When asked why, Andy said "she [girlfriend] got grumpy...she wanted me to stop watching it...she doesn't like it".

Those participants who were partnered in longer term relationships appeared to either feel the need or desire to view pornography or were actively encouraged not to use it by their partners. Garry (49 years old) explained "I've got a missus now, I've got a missus so l'm right". When talking about viewing pornography on the internet Angelo (29 years old) spoke of his partner as the person "who had a bit of a problem with it. She didn't like me looking up that sort of stuff, she didn't like me looking up that". Angelo (29 years old) added "she sort of felt a bit insecure about herself".

In contrast, those participants who were single and actively viewed pornography reported they were encouraged to do so by supportive family members. One participant, Liam (24 years old), regularly viewed pornography. When enquiring as to whether Liam's mother (as he lived at home) knew about his activity, Liam said: "Yes my mum does, my mum knows, she helps me with Facebook, she helps me". Liam (24 years old) explained that his mother allows him to look at pornography: "Only in my room in a private place. In a private place and only at night time... and not in front of people".

Drawing on earlier description about assessing, managing and mitigating risks in online personal safety judgements, participants described being careful about the content that they accessed and viewed. They expressed concern that they did not access exploitative material such as underage or child pornography. Angelo (29 years old) stated "got nothing pretty much against it [pornography] except for the underage, I wouldn't go anywhere near that sort of stuff". Paul (22 years old) stated that when he browses the internet he "stumbles on pictures that are a way too young and it puts [him] right off and [pornography] makes [him] feel bad inside". However Paul (22 years old) explained that he had "got myself into trouble looking at stuff...I got caught by my parents one time, first time I did it I got caught by my parents and they ended up getting a bill of over a thousand dollars. And I ever since I sort of like tried to stay away from it".

Those participants involved in relationships showed great care, concern and caution when being mindful of the type and nature of the material that they were viewing and its consequences. The material was then reported to be used as a means of enhancing their current relationship by expressing their intimacy as it was a joint activity, however was solely driven by the male participants in the company of their female partner.

Another type of online engagement included 'camming'. Jacob (21 years old) explained that he "gets to meet new people on Facebook". When asked if he ever met friends he made on Facebook face-to-face, Jacob (21 years old) said he did "Like as in camera like in the video Messenger. [I] just talk to face to face".

\section{Discussion}

The objective of this research was to explore how people with intellectual disability in Australia engage with online social media and intimate relationships. It is evident from previous research that people with a disability have difficulty accessing technology (Batey \& Waine, 2015; Shakespeare, 2008) and are judged as being unable to express themselves sexually (Brown, 1994; Di Giulio, 2003; Franco et al, 2012; McDonagh, 2007; Murphy, 2003 Sweeney, 2007). The findings of this study however, suggest that those male participants who engaged in internet based viewing of pornography, did so either individually or in mutually exclusive heterosexual relationships. A limitation of this study, it should be noted, is that no sexually diverse participants were 
sampled. Those participants who partnered and viewed pornography were particularly mindful and respectful of their female partner's wishes in how, where and when the material was accessed, viewed and used in relation to their intimate activities. So too, those male participants who used pornography by themselves were able to explore their own sexuality in the privacy of their own home with the support of their parents, particularly mothers.

The findings of this study extend and enhance the seminal work of Löfgren-Mårtenson (2004; 2008) by describing internet based social media activities of older adults with an intellectual disability as they explore intimate relationships. The work of Löfgren-Mårtenson $(2004 ; 2008)$ detailed how younger adults were able to identify and assess online-based personal cyber safety risks, however in practice did not conduct themselves in this manner by practicing unsafe and risky behaviours. Whereas this study contributes to paucity of research about how people with intellectual disability engage online, particularly in relation to the sexual self-expression of older adults, who it was found are also able to identify, assess and formulate strategies to mitigate personal cyber safety risks. The participants in this study, with no formal online safety education, described their rationale and judgement for safe online behaviours when meeting new people. For those participants who desired to meet new people using their personal electronic devices and internet based social media, they described various safe practices such as meeting in a public place and advising others of their arrangements.

This study revealed how people with intellectual disability desire to create and maintain existing relationships using internet based social media, yet, only a few are actively using online mediums to explore their sexuality. What is evident from the participants in this study is that they are actively engaged online using internet based social media messaging service on various personal electronic devices to communicate with known friends and peers through old school friends and work colleagues. This finding addresses the concerns raised by Batey and Waine, (2015); D'Aubin, (2007); Dobransky and Hargittai, (2006); Jaeger, (2012) that people with intellectual disability are stigmatised and isolated. Findings suggest that people with intellectual disability, when they were are able to access personal electronic devices with internet based social media applications, are socially active by arranging to meet up with their known peers for outings. These activities are arranged by sending and receiving messages on their mobile phone, using a message based method. This highlights the various means and methods by which people with intellectual disability are socially engaged with their friendship groups, addressing previous research, with examples provided by participants of arranging going to the mall, movies or 'catching up'.

The following were found for those people with intellectual disability in this study who used internet based social media/going online as a means of participating in an intimate relationship. Firstly, this finding challenges previous research by Bruder and Kroese, (2005) and Sweeney, (2007) in which people with intellectual disability when going online would be vulnerable and exploited as they pursue relationships. The findings of this study suggest that the opposite maybe the current situation; people with intellectual disability are capable of exercising judgement in the type of material they engage and in a respectful manner, by themselves or in their respective consenting relationship. What is needed is further exploration of why this might be. Secondly, a number of participants expressed and mirrored repressive societal beliefs and attitudes from their parents as they described the viewing of 'sexy material' in a negative manner. This finding highlights the continued stereotyping of people with intellectual disability as asexual, childlike and denying their human right to sexual self-expression (Brown, 1994; Di Giulio, 2003; Franco et al, 2012; McDonagh, 2007; Murphy, 2003 Sweeney, 2007). This was evident when participants described how parents or care givers actively denied or repressed and acted as gatekeepers in their attempts to express their sexuality. Thirdly, all of the participants were engaged in heterosexual relationships. This finding notes the absence of diversity in the types of other sexuality that may exist in the intellectual disability community such as gay, lesbian, trans or queer.

\section{Impact and Implications}

Like any qualitative methodology, the findings of this study are not expected to be generalizable for all people with an intellectual disability. However, the findings provide the opportunity to be transferrable by providing important information specific to this cohort of Australian individuals and their experience using internet based social media and intimate relationships. The nature and type of methodology employed in this study means that the findings are grounded in the data and can be considered relevant for other like situations and contexts. 
The impact of the findings of this study is to bring about new knowledge and even suggest a changing situation around previously held beliefs regarding the sexual self-expression of people with intellectual disability. Despite all the intimate relationships being heterosexual, this does not mean that all family caregiver support and education needs to be hetero-centric. When supporting people with intellectual disability in relationships that are diverse, adopt an inclusive discourse or stance, rather than a heteronormative standpoint.

The notion that people with intellectual disability are incapable of engaging online due to being vulnerable and exploited stands in contrast to the findings of this study. Families and caregivers need to embrace that people with intellectual disability can exercise astute judgement to engage safely online. Extending this notion is that people with intellectual disability can exercise appropriate caution when meeting new people highlights their ability to make new friends and support current and existing friendships.

The implications around the findings of this study are broad and suggest the need for ongoing education for families, caregivers and care providers, but also an acceptance that circumstances, society and broad community understanding about cyber safety is changing and more accessible. It appears from the findings that people with intellectual disability are capable of navigating the online world safely and achieve their goals to develop and pursue their existing friendships and relationships. Further, they are able to explore their consensual, monogamous sexual relationships in a safe manner. This means that the societal beliefs and attitudes that people with intellectual disability are asexual, childlike and vulnerable (Brown, 1994; Di Giulio, 2003; Franco et al, 2012; McDonagh, 2007; Murphy, 2003 Sweeney, 2007) do not resonate with the findings of this study. In order to support the human rights of people with intellectual disability to explore and freely express their sexuality, a change in societal beliefs, attitudes and practices is required to cease the perpetuation of this stereotype.

\section{Limitations}

Although the study showed that people with intellectual disability are capable of engaging online, there are limitations which have to be taken into account when discussing our findings in relation to the generalization of its outcomes. First, the findings of this study may not be generalizable in suggesting, that all people with intellectual disability will be able to act in a safe manner when engaging online for intimate relationships. However, there are key transferrable points that can be made which may suggest that older adults are capable of making judgements regarding their own personal safety when engaging online. Transferring this finding suggests that in the absence of formal education regarding online personal cyber safety, people with intellectual disability are able to assess, manage and mitigate risks associated with using personal electronic devices and internet based social media without the intervention of a 'gatekeeper'.

A second limitation of the current study relates to the potential skewing of results due to the lack of gender balance within the cohort of participants in relation to having more male participants than female participants. The resultant sample was due to the third party recruitment as a condition of institutional (Flinders University) review board ethics approval process. In relation to the present study, the views drawn from male participants can be explained by Gagnon and Simon (2005) whose views on sexuality are influenced by gender due to the different socialization processes experienced by males and females. This means the results of the current study might have shown different perspectives if there had been an equal number of male and female participants. Third, the results may well be true for the Australian participants from which the sample is drawn, and not be generalizable to other ethnicities or nationalities beyond that of this cohort.

\section{Conclusion}

This study described the lived experience of people with intellectual disability and their use of internet based social media in forming intimate relationships. Participants with intellectual disability reported their desire to make new friends, along with maintaining existing friendship groups from school, work, social and hobby groups and with work colleagues. A range of personal electronic devices were used by the participants in this study to access the internet and internet based social media. For example they used their personal electronic devices (mobile phone) for sending and receiving short messages (SMS or texts) in communicating with their friends when arranging social activities. Internet based social media was also used to keep in contact with their friends, 
using their mobile phone, and messenger function of the application. When making new friends and meeting for the first time, participants appeared able to assess, manage and mitigate risks associated with maintaining online personal safety.

For those involved in consenting heterosexual monogamous relationships, reports of using the internet and personal electronic devices to view pornography were made. They described engaging with their intimate sexual partner in a respectful manner, being mindful of the content being viewed and to an appropriate level of participation and comfort for their partner. Participants expressed making some effort to consider the content being viewed for suitability, in that they considered whether it was in their view tasteful and not exploitive in content. Those viewing the pornography were mindful of the wishes of their respective partner, in that the content was a shared activity and not mutually exclusive as an expression of intimacy and their sexuality.

The findings further support the ongoing challenges for the human rights of people with intellectual disability in being able to freely express their sexuality, especially using electronic and online technology. Those family members, caregivers, and organisations who support people with intellectual disability need to be mindful of the continued perpetuation of restrictive societal beliefs, attitudes and practices which can limit the sexual selfexpression of people with intellectual disability. There is some evidence that people with intellectual disability are potentially more capable of successfully navigating the 'digital divide' then previously considered and therefore should be allowed to use current technology like the rest of society as a tool to facilitate, enrich and fulfil their desire of engaging in meaningful friendships and intimate relationships.

\section{References}

Amado, A. N., Stancliffe, R. J., McCarron, M., \& McCallion, P. (2013). Social inclusion and community participation of individuals with intellectual/ development disabilities. Intellectual and Developmental Disabilities, 51, 360-375. https://doi.org/10.1352/1934-9556-51.5.360

Batey, G., \& Waine, H. (2015). Safe internet access for service users. Art \& Science, 18(3), 16-20.

Bazzo, G., Nota, L., Soresi, S., Ferrari, L., \& Minnes, P. (2007). Attitudes of social service providers towards the sexuality of individuals with intellectual disability. Journal of Applied Research in Intellectual Disabilities, 20, 110115. https://doi.org/10.1111/j.1468-3148.2006.00308.x

Brown, H. (1994). 'An ordinary sexual life?' A review of the normalisation principle as it applies to the sexual options of people with learning disabilities. Disability \& Society, 9, 123-144.

https://doi.org/10.1080/09687599466780181

Bruder, C., \& Kroese, B. (2005). The efficacy of interventions designed to prevent and protect people with intellectual disabilities from sexual abuse: A review of the literature. The Journal of Adult Protection, 7(2), 13-27. https://doi.org/10.1108/14668203200500009

Chadwick, D., Wesson, C., \& Fullwood, C. (2013). Internet access by people with intellectual disabilities: Inequalities and opportunities. Future Internet, 5, 376-397. https://doi.org/10.3390/fi5030376

Cohen, N. Z., \& Omery, A. (1994). Schools of phenomenology: Implications for research. In J. M. Morse (Ed.), Critical issues in qualitative research methods (pp. 136-156). Thousand Oaks CA: Sage Publications.

Collingridge, D, \& Gantt, E. (2008).The quality of qualitative research. American Journal of Medical Quality, 23, 389395. https://doi.org/10.1177/1062860608320646

Correa, T., Hinsley, A., \& de Zúñiga, H. (2010). Who interacts on the Web?: The intersection of users' personality and social media use. Computers in Human Behavior, 26, 247-253. https://doi.org/10.1016/j.chb.2009.09.003

Craft, A. (1987). Mental handicap and sexuality: Issues and perspectives. Turnbridge Wells: Costello.

Creswell, J.W. (2014). Research design: Qualitative, quantitative, and mixed methods approaches (4 ${ }^{\text {th }}$ ed.). Thousand Oaks, CA: Sage Publications.

Creswell, J., Hanson, W., Clark, P., \& Morales, A. (2007). Qualitative research designs: Selection and implementation. Counselling Psychologist, 35, 236-264. 
D'Aubin, A. (2007). Working for barrier removal in the ICT area: Creating a more accessible and inclusive Canada. The Information Society: An International Journal, 23, 193-201.

Delaney, C. (2003). Walking a fine line: Graduate nurses' transition experiences during orientation. Journal of Nursing Education, 42, 437-443.

DiCicco-Bloom, B., \& Crabtree, B. F. (2006). Making sense of qualitative research: The qualitative interview. Medical Education, 40, 314-321. https://doi.org/10.1111/j.1365-2929.2006.02418.x

Di Giulio, G. (2003). Sexuality and people living with physical or developmental disabilities: A review of key issues. The Canadian Journal of Human Sexuality, 12, 53-68.

Dobransky, K., \& Hargittai, E. (2006). The disability divide in internet access and use. Information, Communication \& Society, 9, 313-334. https://doi.org/10.1080/13691180600751298

Dowling, M., \& Cooney, A. (2012). Research approaches related to phenomenology: Negotiating a complex landscape. Nurse Researcher, 20, 21-27. https://doi.org/10.7748/nr2012.11.20.2.21.c9440

Flood, A. (2010). Understanding phenomenology. Phenomenology, 17(2), 7-15.

Fossey, E., Harvey, C., McDermott, F., \& Davidson, L. (2002). Understanding and evaluating qualitative research. Australian and New Zealand Journal of Psychiatry, 36, 717-732. https://doi.org/10.1046/j.1440-1614.2002.01100.x

Franco, D. G., Cardoso, J., \& Neto, I. (2012). Attitudes towards affectivity and sexuality of people with intellectual disability. Sexuality and Disability, 30, 261-287. https://doi.org/10.1007/s11195-012-9260-x

Gagnon, J. H., \& Simon, W. (2005). Sexual Conduct. The Social Sources of Human Sexuality (2 ${ }^{\text {nd }}$ ed.). New Brunswick, London: Aldine Transaction.

Goggin, G. (2009). Disability, media, and the politics of vulnerability. Research Online, 1(19), 1-13.

Gutiérrez, P., \& Martorell, A. (2011). People with intellectual disability and ICTs/Las personas con discapacidad intelectual ante las TIC. Comunicar, 18(36), 173-180. https://doi.org/10.3916/C36-2011-03-09

Hollomotz, A. (2011). Learning difficulties and sexual vulnerability: A social approach. London: Jessica Kingsley Publishers.

Jaeger, P. T. (2012). Disability and the Internet: Confronting a digital divide. Disability and the Internet. Lynne Rienner Publishers.

Kulick, D., \& Rydström, J. (2015). Loneliness and its opposite: Sex, disability, and the ethics of engagement. Duke University Press.

Lazar, J., \& Jaeger, P. (2011). Reducing Barriers to online access for people with disabilities. Issues in Science and Technology, 27(2), 69-82.

Lester, S. (1999). An introduction to phenomenological research. Taunton UK: Stan Lester Developments. Retrieved from https://www.rgs.org/NR/rdonlyres/F50603E0-41AF-4B15-9C84-

BA7E4DE8CB4F/0/Seaweedphenomenologyresearch.pdf

Liamputtong, P. (2009). Qualitative data analysis: Conceptual and practical considerations. Health Promotion Journal of Australia, 20, 133-139.

Lincoln, Y. S., \& Guba, E. G. (1985). Naturalistic inquiry. Beverly Hills, CA: Sage.

Löfgren-Mårtenson, L. (2004). "May I?" About sexuality and love in the new generation with intellectual disabilities. Sexuality and Disability, 22, 197-207. https://doi.org/10.1023/B:SEDI.0000039062.73691.cb

Löfgren-Mårtenson, L. (2008). Love in cyberspace: Swedish young people with intellectual disabilities and the Internet. Scandinavian Journal of Disability, 10, 125-138. https://doi.org/10.1080/15017410701758005

Lowes, L., \& Prowse, M. A. (2001). Standing outside the interview process? The illusion of objectivity in phenomenological data generation. International Journal of Nursing Studies, 38, 471-480.

https://doi.org/10.1016/S0020-7489(00)00080-8 
MacDougall, C., \& Fudge, E. (2001). Planning and recruiting the sample for focus groups and in-depth interviews. Qualitative Health Research, 11, 117-126. https://doi.org/10.1177/104973201129118975

Mackey, S. (2005). Phenomenological nursing research: Methodological insights derived from Heidegger's interpretive phenomenology. International Journal of Nursing Studies, 42, 179-186.

https://doi.org/10.1016/j.ijnurstu.2004.06.011

McCarthy, M. (2014). Women with intellectual disability: Their sexual lives in the 21st century, Journal of Intellectual and Developmental Disability, 39, 24-131. https://doi.org/10.3109/13668250.2014.894963

McDonagh, R., (2007). Too sexed-up! The Journal of Adult Protection, 9(4), 27-33.

https://doi.org/10.1108/14668203200700025

McRuer, R., \& Mollow, A. (2012). Sex and disability. Duke University Press.

Murphy, G. H. (2003). Capacity to consent to sexual relationships in adults with learning disabilities. Journal of Family Planning and Reproductive Health, 29, 148-149. https://doi.org/10.1783/147118903101197520

Parchomiuk, M. (2012). Model of intellectual disability and the relationship of attitudes towards the sexuality of persons with an intellectual disability. Sexuality and Disability, 31, 125-139. https://doi.org/10.1007/s11195-0129285-1

Parley, F. (2010). What does vulnerability mean? British Journal of Learning Disabilities, 39, 266-276.

https://doi.org/10.1111/j.1468-3156.2010.00663.x

Pietkiewicz, I., \& Smith, J. A. (2014). A practical guide to using Interpretative Phenomenological Analysis in qualitative research psychology. Psychological Journal, 20(1), 7-14.

Priest, H. (2002). An approach to the phenomenological analysis of data. (Issues in research). Nurse Researcher, 10(2), 50-63.

Raacke, J., \& Bonds-Raacke, J. (2008). MySpace and Facebook: Applying the uses and gratifications theory to exploring friend-networking sites. CyberPsychology \& Behavior, 11, 169-174.

https://doi.org/10.1089/cpb.2007.0056

Reid, G. G., \& Boyer, W. (2013). Social network sites and young adolescent identity development. Childhood Education, 89, 243-253. https://doi.org/10.1080/00094056.2013.815554

Rogers, C. (2009). (S)excerpts from a life told: Sex, gender and learning disability. Sexualities, 12, 270-288. https://doi.org/10.1177/1363460709103891

Seymour, D., \& Lupton, W. (2000). Technology, selfhood and physical disability. Social Science \& Medicine, 50, 1851-1862. https://doi.org/10.1016/S0277-9536(99)00422-0

Shakespeare, T. (2008). Debating disability. Journal of Medical Ethics, 34, 11-14.

Shakespeare, T., Gillespie-Sells, K., \& Davies, D. (1996). The sexual politics of disability: Untold desires. Burns \& Oates.

Smith, J A. (1996). Beyond the divide between cognition and discourse: Using interpretative phenomenological analysis in health psychology. Psychology and Health, 11, 261-271. https://doi.org/10.1080/08870449608400256

Smith, J., \& Osborne, M. (2003). Interpretative phenomenological analysis. In J. A. Smith (Ed.), Qualitative psychology. A practical guide to research methods (pp. 51-80). London: Sage Publications.

Smith, J., Flowers, P., \& Larkin, M. (2009). Interpretative phenomenological analysis: Theory, method and research. London: Sage Publications.

Stendal. K. (2012). How do people with disability use and experience virtual worlds and ICT: A literature review. Virtual Worlds Research, 5(1), 1-17.

Swango-Wilson, A. (2010). Systems theory and the development of sexual identity for individuals with intellectual/developmental disability. Sexuality and Disability, 28, 157-164. https://doi.org/10.1007/s11195-0109167-3 
Sweeney, L. (2007). The importance of human sexuality education for students with disability. The Exceptional Parent, 37(9), 36-39.

Todres, L., \& Wheeler, S. (2001). The complementarity of phenomenology, hermeneutics and existentialism as a philosophical perspective for nursing research. International Journal of Nursing Studies, 38(1), 1-8.

https://doi.org/10.1016/S0020-7489(00)00047-X

United Nations (2006). The United Nations Convention on the Rights of Persons with Disabilities. USA: Author.

Van der Zalm, J., \& Bergum, V. (2000). Hermeneutic-phenomenology: Providing living knowledge for nursing practice Journal of Advanced Nursing, 31, 211-218. https://doi.org/10.1046/j.1365-2648.2000.01244.x

\section{Correspondence to:}

Judith Darragh

GPO Box 2100

Adelaide, South Australia, 5001

Room S216, South Wing, Sturt Campus

Email: judith.darragh@flinders.edu.au 


\section{Appendix: Interview Guide}

List of Conversation Guide Aimed at Obtaining Relevant Data from individuals with intellectual disability

Individual with Intellectual Disability

Alternate questions when response is NO

Some of the questions I am going to ask you may be sensitive - I do not want to embarrass or upset you.

If any questions make you feel uncomfortable you can stop any time you like, just let me know.

You do not have to answer any question you do not want to.

I am not going to be upset with you.

I am going to keep what you tell me private.

\begin{tabular}{|c|c|}
\hline Pseudonym & \\
\hline \multicolumn{2}{|l|}{ Number } \\
\hline \multicolumn{2}{|l|}{ Date } \\
\hline \multicolumn{2}{|l|}{ Age } \\
\hline \multicolumn{2}{|l|}{ Gender } \\
\hline \multicolumn{2}{|l|}{ Interview } \\
\hline \multicolumn{2}{|l|}{ Tell me about yourself? } \\
\hline \multicolumn{2}{|l|}{ What do you do in a day? } \\
\hline \multicolumn{2}{|l|}{ Do you go to work? ...to school? Day program? } \\
\hline \multicolumn{2}{|l|}{ Where do you live? } \\
\hline \multicolumn{2}{|l|}{ Who lives with you? } \\
\hline \multicolumn{2}{|l|}{ What other care support do you need? } \\
\hline \multicolumn{2}{|l|}{ Tell me about your ongoing care you think you need. } \\
\hline \multicolumn{2}{|l|}{ What do you like about where you live? } \\
\hline \multicolumn{2}{|l|}{ Tell me about your friends? } \\
\hline \multicolumn{2}{|l|}{$\begin{array}{l}\text { How do you keep in contact with everyone? } \\
\text { If Social Media ask: } \\
\text { Who provided you with the tools? } \\
\text { Who pays for the mobile, internet etc? }\end{array}$} \\
\hline \multicolumn{2}{|l|}{ How do you make plans to see each other? } \\
\hline \multicolumn{2}{|l|}{$\begin{array}{l}\text { Where do you see them? } \\
\text { - } \quad \text { At work? } \\
\text { - } \quad \text { In your street? } \\
\text { - } \quad \text { Other places? }\end{array}$} \\
\hline \multicolumn{2}{|l|}{ Can you tell me more? } \\
\hline Do you use the telephone? & \multirow{3}{*}{$\begin{array}{l}\text { Would you like to? } \\
\text { Could you tell me why? }\end{array}$} \\
\hline Do you use a computer/internet/tablet? & \\
\hline Do you use an IPad or smart phone? & \\
\hline $\begin{array}{l}\text { Do you have a computer, smart phone, tablet at } \\
\text { home? } \\
\text { If yes: } \\
\text { Who bought it? } \\
\text { Where do you use it? } \\
\text { Internet connection? }\end{array}$ & $\begin{array}{l}\text { Would you like any of these? } \\
\text { Could you tell me why? }\end{array}$ \\
\hline \multicolumn{2}{|l|}{$\begin{array}{l}\text { What kind of things do you do on them? } \\
\text { What do you use them for? }\end{array}$} \\
\hline \multicolumn{2}{|l|}{ What do they help you to do? } \\
\hline \multicolumn{2}{|l|}{$\begin{array}{l}\text { Do you have any friends who use any/all of these } \\
\text { things? }\end{array}$} \\
\hline \multicolumn{2}{|l|}{ What do you think about that? } \\
\hline Have you used Facebook or twitter? & Is there a reason you haven't used Facebook or twitter? \\
\hline When you used Facebook or twitter to make friends & Is there anything stopping you now? \\
\hline
\end{tabular}




\begin{tabular}{|c|c|}
\hline how have you done this? & \\
\hline $\begin{array}{l}\text { Did you meet face to face before you became friends } \\
\text { on Facebook? Tell me about it. }\end{array}$ & \\
\hline $\begin{array}{l}\text { Do you get to meet new people? } \\
\text { Tell me more... }\end{array}$ & \\
\hline $\begin{array}{l}\text { Do you have friends who you have never met face to } \\
\text { face? } \\
\text { Tell me how you would go about 'unfriending } \\
\text { someone. }\end{array}$ & \\
\hline $\begin{array}{l}\text { What would you do if you didn't want to be friends } \\
\text { with someone on Face book anymore? }\end{array}$ & \\
\hline $\begin{array}{l}\text { Is that alright? } \\
\text { Tell me more... }\end{array}$ & \\
\hline $\begin{array}{l}\text { Tell me how you will keep yourself safe on the } \\
\text { internet? } \\
\text { Who taught you that? }\end{array}$ & \\
\hline $\begin{array}{l}\text { Have you ever arranged to meet anybody you met on } \\
\text { the internet? } \\
\text { Tell me more about what happened } \\
\text { How was that experience? }\end{array}$ & \\
\hline $\begin{array}{l}\text { How would you keep yourself safe if you met with } \\
\text { someone face to face you first met on the internet? }\end{array}$ & \\
\hline ** & \\
\hline $\begin{array}{l}\text { Are you interested in doing things that make you } \\
\text { feel sexy? } \\
\text { Tell me more about things you like to do. }\end{array}$ & $\begin{array}{l}\text { Would you like to? } \\
\text { Can you tell me why? } \\
\text { Why isn't it important to you? } \\
\text { Do you not think feeling sexy is important to you? } \\
\text { Or has someone told you something about feeling } \\
\text { sexy? }\end{array}$ \\
\hline $\begin{array}{l}\text { Can I ask what kind of things you need to feel } \\
\text { sexy? }\end{array}$ & $\begin{array}{l}\text { Remember I told you that some of the questions I was } \\
\text { going to ask you might be sensitive - I do not want to }\end{array}$ \\
\hline Tell me more. & embarrass or upset you. \\
\hline $\begin{array}{l}\text { Do you look at pictures to feel sexy? } \\
\text { Tell me about your experience doing this. }\end{array}$ & $\begin{array}{l}\text { If any questions make you feel uncomfortable you can stop } \\
\text { any time you like. }\end{array}$ \\
\hline Do you talk to people to feel sexy? & You do not have to answer any question you do not want \\
\hline What happens inside your head? & \\
\hline $\begin{array}{l}\text { What happens inside of your body? } \\
\star \star\end{array}$ & I am not going to be upset with you. \\
\hline $\begin{array}{l}\text { Lots of people like to look at sexy things on the } \\
\text { internet.....What do you think about that? }\end{array}$ & \\
\hline $\begin{array}{l}\text { Have you ever looked at sexy pictures on websites } \\
\text { that have made you feel sexy? }\end{array}$ & $\begin{array}{l}\text { Can you tell me why you haven't? } \\
\text { Not interested? }\end{array}$ \\
\hline Would you be willing to talk about those websites? & \\
\hline Tell me more. & \\
\hline $\begin{array}{l}\text { What do you think about seeing sexy pictures on } \\
\text { websites? }\end{array}$ & \\
\hline How does it make you feel? & \\
\hline $\begin{array}{l}\text { Have you ever gone to look for them again or to look } \\
\text { for more? } \\
\text { Tell me about a time that you did. } \\
\text { Tell me why not. }\end{array}$ & \\
\hline
\end{tabular}




\section{About Authors}

Judith Darragh is a PhD Candidate with degrees in Behavioural Science (Psych), Disability Studies Honours (First Class) and Master of Social work, all from Flinders University, Adelaide. Judith is undertaking this study around sexual expression and social media access for people living with intellectual disability. Judith works as a tutor in the Bachelor of Disability and Development Education.

Dr Louise Reynolds is an independent researcher whose publications, teaching and professional involvement involve interests in disability, Australian Health Care System, pre-hospital care and qualitative methodologies.

Assoc. Prof Caroline Ellison is an Associate Professor in Disability and Community Inclusion, School of Health Sciences, Flinders University and the Assistant Dean of International for the School of Health Science. Her research, publications, teaching and professional involvement are in areas such as sexuality and Disability, Community Inclusion, Person Centred Active Support, and Leisure, Arts and Sport.

Dr Michelle Bellon is a Senior Lecturer in Disability and Community Inclusion, School of Health Sciences, Flinders University. Her research, publications, teaching and professional involvement combine interests in epilepsy, acquired brain injury, community integration and family/care-giver supports.

Editorial record: First submission received on September 9, 2016. Revision received on January 4, 2017. Accepted for publication on May 5, 2017. The article is part of Special Issue "Internet use and disability - Risks, opportunities and challenges" guest edited by Emma Sorbring and Martin Molin. 